\title{
Article \\ Low Heat Availability Could Limit the Potential Spread of the Emerald Ash Borer to Northern Europe (Prognosis Based on Growing Degree Days per Year)
}

\author{
Marina J. Orlova-Bienkowskaja * (D) and Andrzej O. Bieńkowski
}

check for updates

Citation: Orlova-Bienkowskaja, M.J.; Bieńkowski, A.O. Low Heat Availability Could Limit the Potential Spread of the Emerald Ash Borer to Northern Europe (Prognosis Based on Growing Degree Days per Year). Insects 2022, 13, 52. https:/ / doi.org/ $10.3390 /$ insects 13010052

Academic Editor: Dimitrios N. Avtzis

Received: 23 October 2021

Accepted: 28 December 2021

Published: 2 January 2022

Publisher's Note: MDPI stays neutral with regard to jurisdictional claims in published maps and institutional affiliations.

Copyright: (c) 2022 by the authors. Licensee MDPI, Basel, Switzerland. This article is an open access article distributed under the terms and conditions of the Creative Commons Attribution (CC BY) license (https:// creativecommons.org/licenses/by/ $4.0 /)$.

\author{
A.N. Severtsov Institute of Ecology and Evolution, Russian Academy of Sciences, 119071 Moscow, Russia; \\ bienkowski@yandex.ru \\ * Correspondence: marinaorlben@yandex.ru
}

\begin{abstract}
Simple Summary: Emerald ash borer is a devastating pest of ash trees. This beetle, native to Asia and established in North America, European Russia and Ukraine is quickly spreading and approaching the borders of the European Union. We made the first prognosis of the potential range of this pest in Europe based on heat availability. Our calculations have shown that, in most European countries, the climate is warm enough for the establishment of the emerald ash borer. However, this pest would probably not be able to establish itself in some regions of Norway, Sweden, Finland, Ireland and Great Britain, because there is not enough heat to complete development (the summer is too cold and too short). Therefore, there is a hope that European ash (Fraxinus excelsior) could escape from the emerald ash borer in some parts of the British Isles and Scandinavia.
\end{abstract}

\begin{abstract}
Emerald ash borer Agrilus planipennis (Coleoptera: Buprestidae) is one of 20 priority quarantine pests of the European Union. It is native to Asia and is established in the USA, Canada, European Russia, and Ukraine. We made the first prognosis of the potential range of $A$. planipennis in Europe based on heat availability. Mean annual growing degree days base $10{ }^{\circ} \mathrm{C}\left(\mathrm{AGDD}_{10}\right)$ was calculated for each grid square $\left(0.25^{\circ} \times 0.25^{\circ}\right.$ latitude $x$ longitude degrees $)$ on the Earth's surface. Minimal $\mathrm{AGDD}_{10}$ recorded in the grid squares currently occupied by A. planipennis was $714^{\circ}$ in Asia, $705^{\circ}$ in North America, and $711^{\circ}$ in European Russia. Agrilus planipennis has never been recorded in localities with $\mathrm{AGDD}_{10}$ below $700^{\circ}$. If the phenotypic plasticity would not allow this species to overcome this threshold, cold regions of Europe would probably not be invaded by A. planipennis. Thus, Fraxinus excelsior could potentially escape from A. planipennis in some regions of Norway, Sweden, Finland, Ireland, and Great Britain.
\end{abstract}

Keywords: emerald ash borer; EAB; Buprestidae; jewel beetles; Coleoptera; Fraxinus; forest pest

\section{Introduction}

Emerald ash borer Agrilus planipennis (Fairmaire, 1888) (Coleoptera: Buprestidae) is an alien pest of ash trees (Fraxinus spp.) in the USA, Canada, European Russia and Ukraine [1,2]. This beetle, native to East Asia [3], was first recorded in North America in 2002, in Michigan [4] and in Europe in 2003, in Moscow [5]. Since that time, the pest has been spreading over both continents and killing millions of ash trees. Agrilus planipennis is a major threat to ash trees in Europe; it is included in the list of 20 priority quarantine pests of the European Union (EU) [6,7]. Now, the border of the A. planipennis range is just $120 \mathrm{~km}$ from the border of the EU; A. planipennis will inevitably appear in the EU soon [8,9]. The most commonly infested ash trees in European Russia and Ukraine are the green ash, Fraxinus pennsylvanica Marsh. This ash species was introduced for landscape plantings from North America in the 20th century and is known to be highly susceptible to emerald ash borer [10]. All ash species native to Europe (Fraxinus excelsior L., F. ornus L. and F. angustifolia Vahl.) are susceptible to A. planipennis [11]. It is very important to assess the 
potential range of the species in Europe, since it is an essential part in planning measures to mitigate economic and ecological losses from the future outbreak.

Climate and distribution of susceptible host plants are critical factors considered in predicting the potential distributions of alien species including A. planipennis [12]. Several prognoses of the potential range in Europe based on different approaches have been made [13-15]. Since the main factor limiting A. planipennis distribution is host availability, a high-resolution map of $A$. planipennis invasion risk for southern central Europe (Austria, Switzerland, Liechtenstein, southern Germany) was based on the distribution of ash trees F. excelsior [13]. Another model based on the maximum entropy modelling (MaxEnt) used the combination of 19 climatic parameters has shown that the regions of Europe adjacent to the known range of $A$. planipennis are suitable for this species; therefore, the climatic factors would not prevent the spread to adjacent regions [14]. The prognosis based on the minimum winter temperature as a possible limiting factor has shown that low winter temperatures would not prevent the spread of $A$. planipennis in all regions of Europe, except some eastern districts of European Russia [15].

Heat availability is one of the main factors determining the distribution of insect species [16]. The distribution of insects to the cold regions is often limited by the amount of heat (degree days) necessary to complete the life cycle. For example, the distribution of the two spotted oak buprestid, Agrilus biguttatus Fabricus, in Europe is limited by this factor [17]. It was hypothesized that low heat availability could limit the spread of A. planipennis to the north [18]. The only prognosis of A. planipennis potential range taking into account heat availability was recently made for Great Britain [19].

Here, we present the first prognosis of $A$. planipennis potential spread in the whole of Europe based on heat availability. Our calculations indicate that this climatic parameter could limit the potential spread of A. planipennis to Northern Europe.

\section{Materials and Methods}

\subsection{Occurrences of Agrilus planipennis}

We compiled a table of occurrences of A. planipennis in Asia, North America and Europe (Table S1) using the information from current databases and articles [1-3,20,21]. The new occurrence in the city of Azov was added to the table (Table S1). We detected characteristic exit holes and larval galleries and collected one dead adult A. planipennis from under the bark of Fraxinus pennsylvanica in the city of Azov on 8 September 2021. It is the first record of $A$. planipennis in the Rostov Region and the most south-western locality of the current range.

\subsection{Calculation of Annual Growing Degree Days}

The data on air temperature for each day from the beginning of 2003 through the end of 2020 were obtained from the ERA5-Land Global Atmospheric Reanalysis dataset for each grid square $\left(0.25^{\circ} \times 0.25^{\circ}\right.$ latitude $\times$ longitude degrees $)$ on the Earth's surface [22] We have chosen these last 18 years because $A$. planipennis was first recorded in Europe in 2003 [5]. The year of the first record always differs from the year of the establishment of the population. We can never know exactly when $A$. planipennis was established in the particular locality. Mean AGDD of an 18 year is an integrated parameter which gives us the general information about average heat availability in the particular locality.

The life cycle of $A$. planipennis in the colder regions (in particular, in Moscow) is 2 years, i.e., the larvae develop under the bark all year-round [23]. Therefore, the annual growing degree days (AGDD) were chosen as a parameter for the prognosis of the potential range. The base temperature of $10{ }^{\circ} \mathrm{C}$ was chosen because it is a standard base temperature previously used in the studies on A. planipennis phenology [24].

The mean $\mathrm{AGDD}_{10}$ were calculated in each grid square as follows:

1. The daily mean temperature was calculated for each day as a mean of the temperatures at 00:00, 02:00, 04:00, 06:00, 08:00, 10:00, 12:00, 14:00, 16:00, 18:00, 20:00 and 22:00 UTC. 
2. Then the growing degree days base $10^{\circ} \mathrm{C}$ from 1 January to 31 December were calculated for each year since 2003 to 2020 (AGDD 10 in each particular year).

3. Then the mean AGDD 10 per year in 2003-2020 was calculated.

A detailed description of the calculation method and the computer code used is provided in the Supplementary Material (File S1). The results of the calculations are provided in the Excel table (Table S2).

\subsection{Analysis and Visualisation of Results}

The analysis of $\mathrm{AGDD}_{10}$ in each grid square occupied by A. planipennis in Asia, North America, European Russia and Ukraine allowed us to determine the minimum AGDD $_{10}$ recorded in the occupied grid squares. Then we made a map of $\mathrm{AGDD}_{10}$ distribution in Europe and revealed the regions of Europe where $\mathrm{AGDD}_{10}$ is less than this threshold. The visualization was created using DIVA-GIS 7.5 [25]. The source of information for the F. excelsior range was the chorological maps for the main European woody species [26].

Shape files of countries and administrative units were obtained from DIVA GIS Free Spatial Data [27]. Shape files of the F. excelsior range, countries and administrative units were published in open-access sources published under a creative commons license [26,27].

\section{Results}

\subsection{Heat Availability in the Regions Currently Occupied by A. planipennis}

$\mathrm{AGDD}_{10}$ in the grid squares currently occupied by A. planipennis varies from 705 to 3676 (Table 1).

Table 1. Minimum and maximum mean $\mathrm{AGDD}_{10}$ in $2003-2020\left({ }^{\circ} \mathrm{C}\right)$ in the grid squares currently occupied by A. planipennis in different continents.

\begin{tabular}{ccc}
\hline Continent & Minimum & Maximum \\
\hline Asia & 714 & 2778 \\
North America & 705 & 3676 \\
Europe (Russia and Ukraine) & 711 & 2046 \\
\hline
\end{tabular}

The distribution of $\mathrm{AGDD}_{10}$ in the current range of A. planipennis is shown in Figures 1-3. The minimum values of $\mathrm{AGDD}_{10}$ recorded in Asia, North America and European Russia are very close to each other: slightly more than $700^{\circ}$. Agrilus planipennis has never been recorded in the grid squares with $\mathrm{AGDD}_{10}$ less than $700^{\circ}$.

The distribution of $A$. planipennis in its native range is not only limited by distribution of its host plants [12]. The host plant of A. planipennis in Asia, Fraxinus mandshurica Rupr., [28] occurs on the Sakhalin Island, some districts of Primorye Territory and Khabarovsk Territory, although A. planipennis is absent there [29] (Figure 4). The minimum heat availability $\left(\mathrm{AGDD}_{10}\right)$ in grid squares occupied by $F$. mandshurica is $574^{\circ}$, while A. planipennis has been never recorded in the grid squares with $\mathrm{AGDD}_{10}$ below $700^{\circ}$. It indicates that heat availability could be one of the factors limiting the distribution of A. planipennis in the north of its range.

\subsection{Heat Availability in Europe}

\subsubsection{General Distribution of Heat Availability}

The map of the heat availability over the whole Europe is shown in Figure 5. In the majority of Europe, $\mathrm{AGDD}_{10}$ is above $700^{\circ}$. However, in the North (Norway, Sweden, Finland, Great Britain, Ireland, north of European Russia) and some mountain territories (the Carpathians, Pyrenees, Alps, Caucasus) there are regions where AGDD 10 is below this threshold.

Ash trees of different species are often planted outside their native ranges in Europe. Survival of these artificial plantings is important, but more important is the survival of ash trees in their native ranges, since ash trees play an important role in the communities of 
broad-leaved forests; hundreds of species of animals, plants and fungi ecologically depend on Fraxinus spp. [7]. The native range of F. excelsior occupies almost the whole of Europe, except the very south and very north (Figure 6). The heat availability is higher than $700^{\circ}$ in the most part of the range, except some northern and mountain regions.

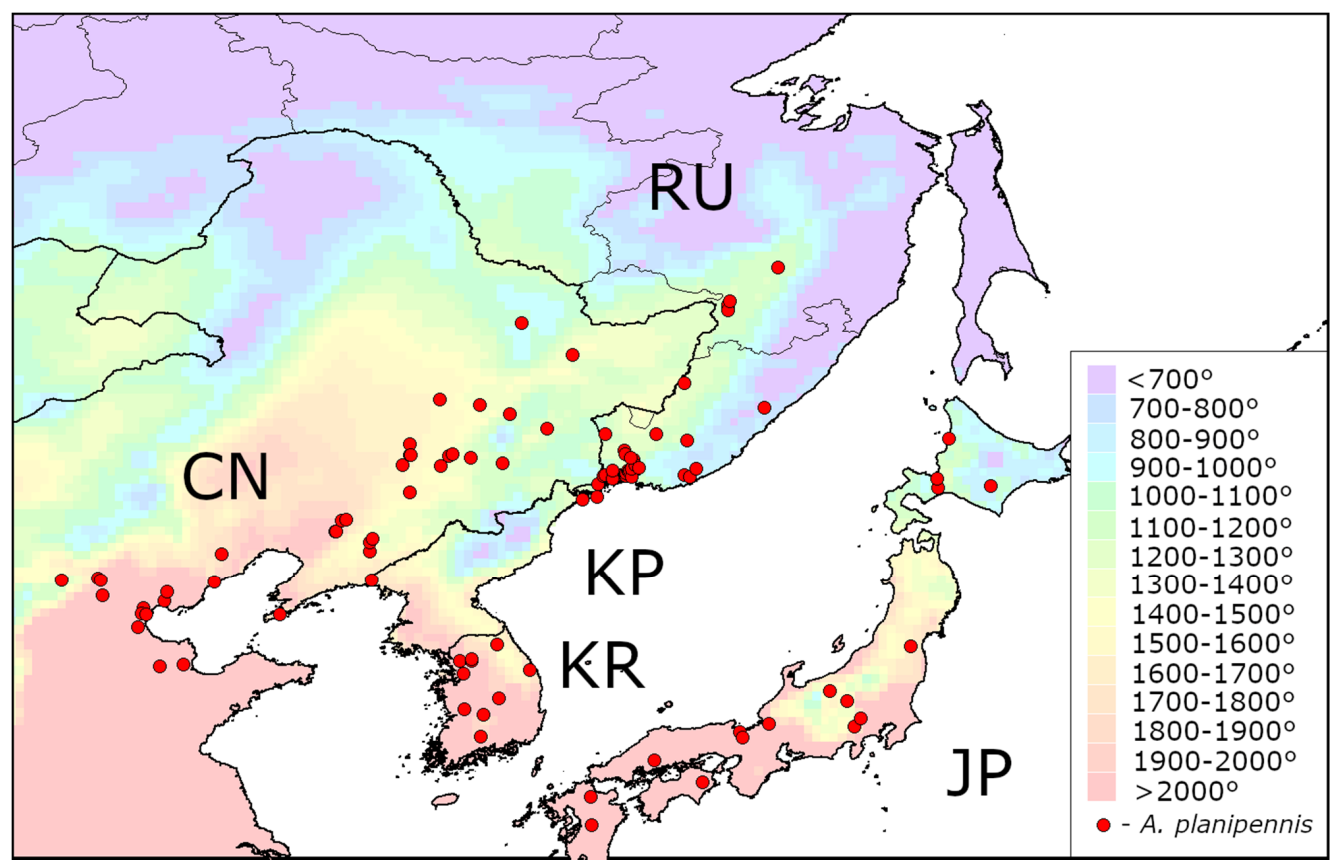

Figure 1. Heat availability in the native range of Agrilus. planipennis in Asia. Mean $\mathrm{AGDD}_{10}$ per year in 2003-2020 is indicated with colours (see the legend). CN-China, JP-Japan, KP-Democratic People's Republic of Korea, KR-Republic of Korea, RU—Russia. The information about occurrences of A. planipennis was obtained from the review of its native range [3].

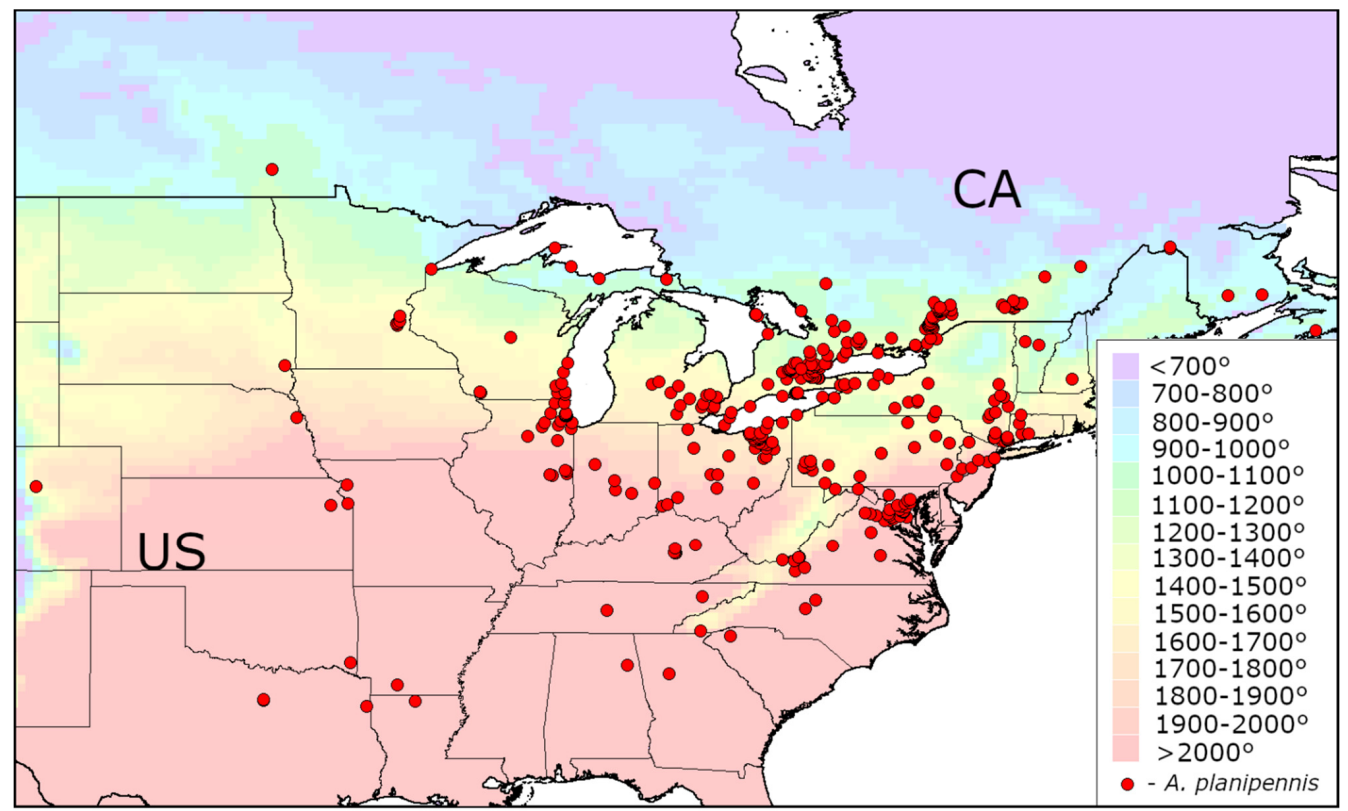

Figure 2. Heat availability in the current invasive range of Agrilus. planipennis in North America. Mean AGDD 10 per year in 2003-2020 is indicated with colours (see the legend). CA-Canada, USUnited States. The information about occurrences of Agrilus planipennis was obtained from Emerald Ash Borer Info and Global Biodiversity Information Facility [1,21]. 


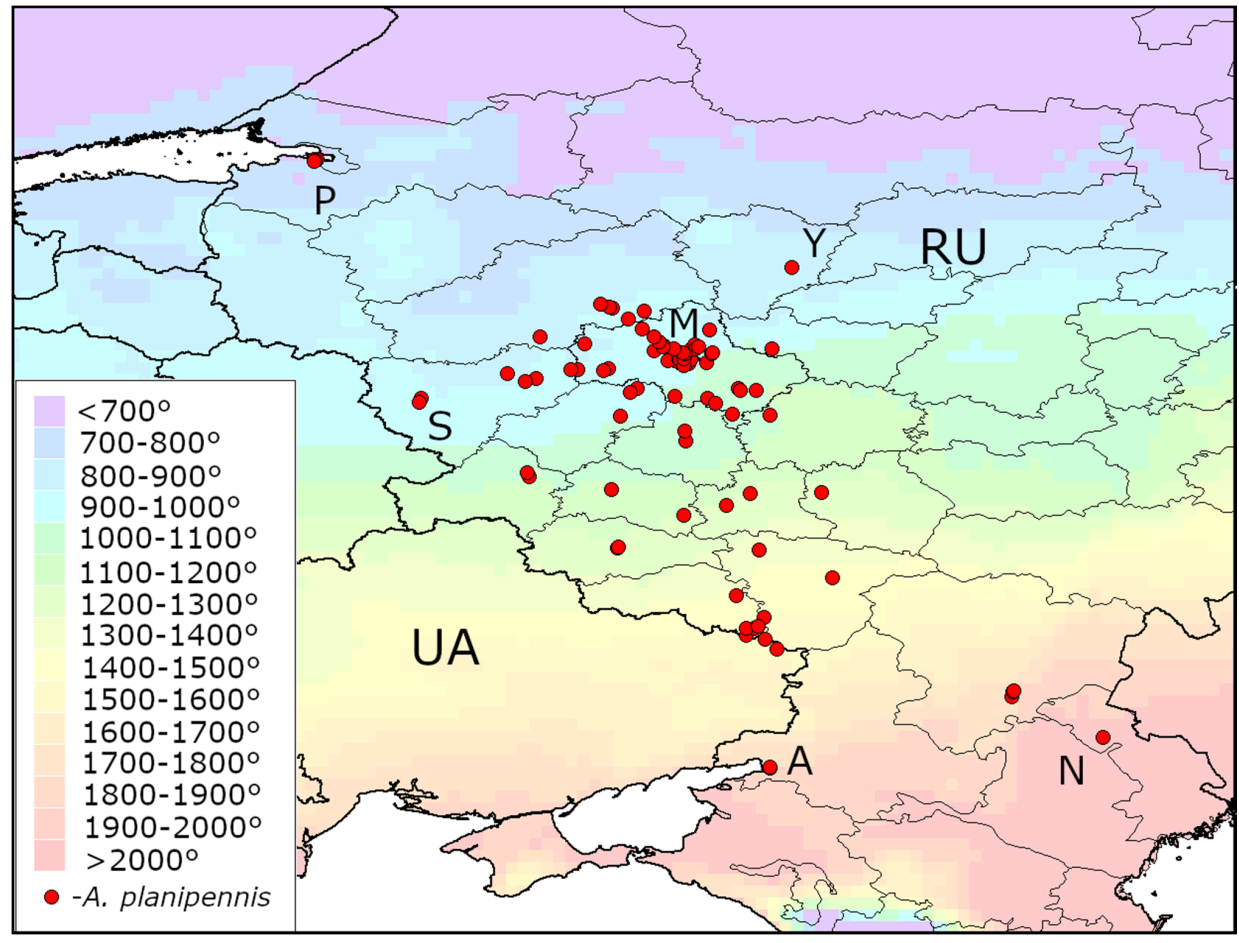

Figure 3. Heat availability in the current range of Agrilus planipennis in European Russia and Ukraine. Mean AGDD 10 per year in 2003-2020 is indicated with colours (see the legend). RURussia, UA-Ukraine. The information about occurrences of A. planipennis was obtained from recent publications $[9,19]$. Some occurrences are indicated with letters: A-Azov, M-Moscow, P-Saint Petersburg, S-Smolensk, Y-Yaroslavl, N-Nikolskoe Village (Astrakhan Region). The new occurrence in Azov is published for the first time.

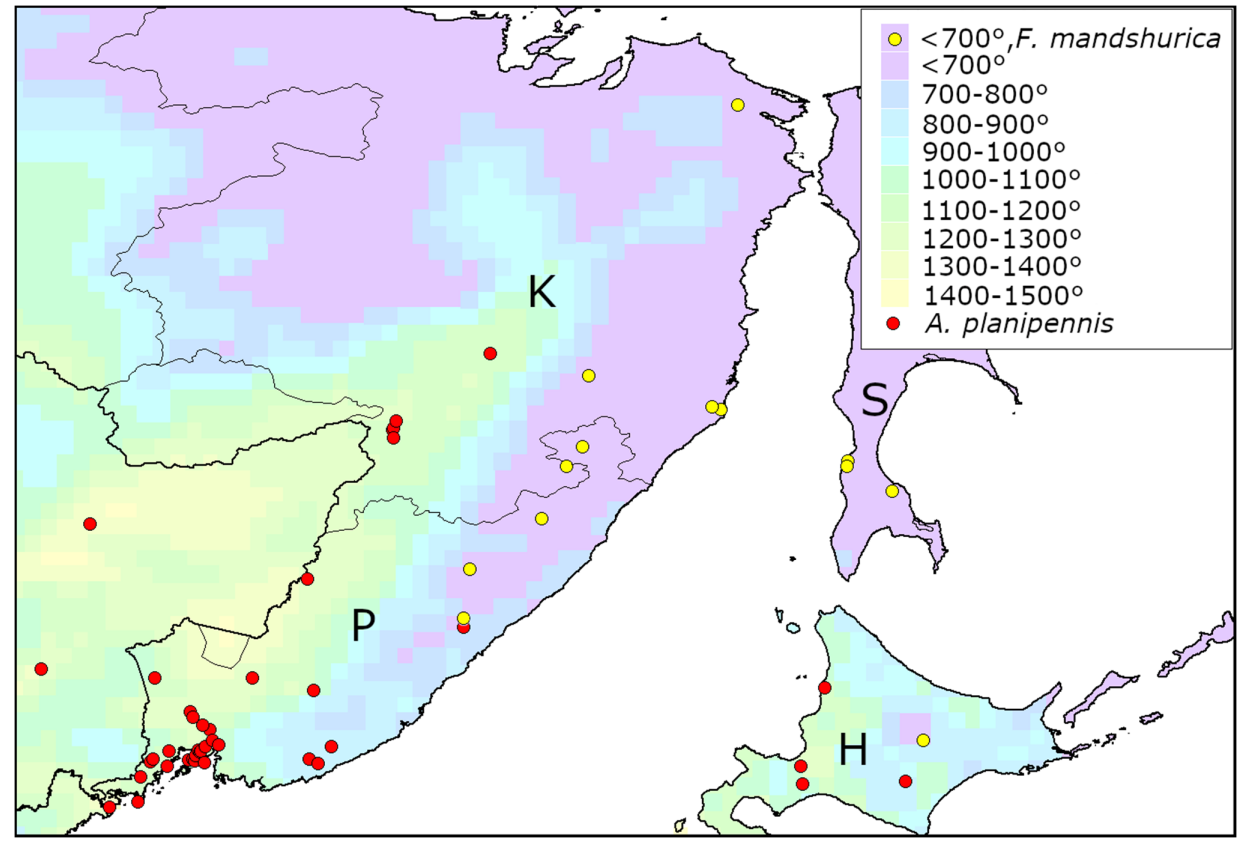

Figure 4. Distribution of Agrilus planipennis and its host plant Fraxinus mandshurica in the northern part of A. planipennis native range in Asia. Mean AGDD $_{10}$ per year in 2003-2020 is indicated with colours (see the legend). Sources of the information on occurrences: A. planipennis-recent review of the native range [3], Fraxinus mandshurica-Global Biodiversity Information Facility [29]. Only localities of F. mandshurica in the grid squares with $\mathrm{AGDD}_{10}$ less than $700^{\circ}$ are shown. 


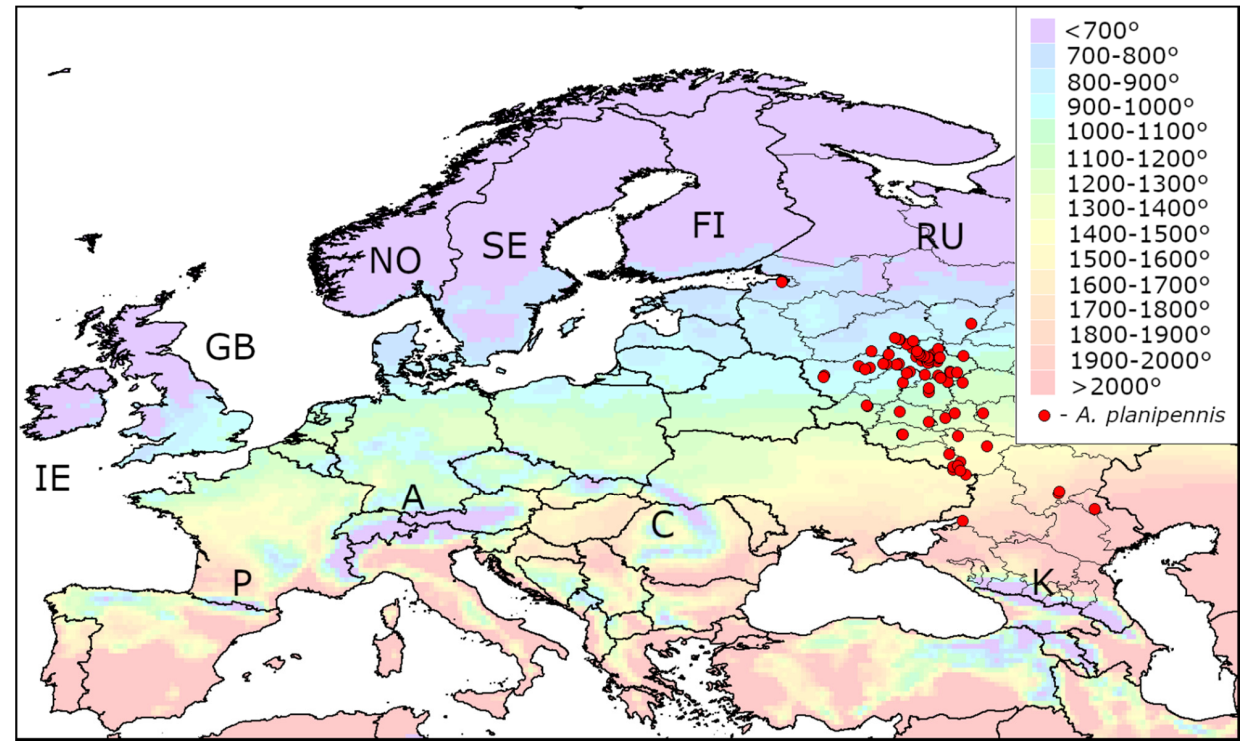

Figure 5. Heat availability in Europe. Mean AGDD 10 per year in 2003-2020 is indicated with colours (see the legend). The information about occurrences of Agrilus planipennis was obtained from recent publications [9,19]. IE-Ireland, GB-Great Britain, NO-Norway, SE-Sweden, FI-Finland, RURussia, A-Alps, C-Carpathians, $\mathrm{K}$-Caucasus, $\mathrm{P}$-Pyrenees.

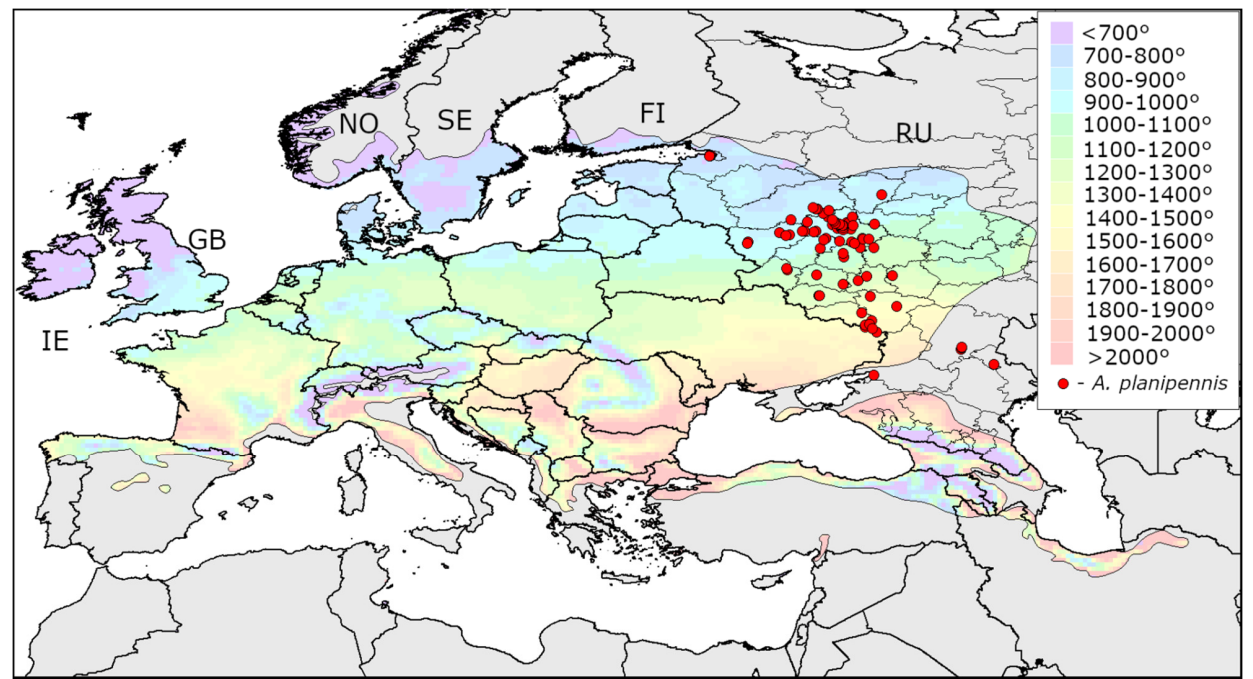

Figure 6. Heat availability in the native range of Fraxinus excelsior in Europe. Mean $\mathrm{AGDD}_{10}$ per year in 2003-2020 within the native range of F. excelsior is indicated with colours (see the legend). FI-Finland, GB—Great Britain, IE-Ireland, NO—Norway, RU—Russia, SE-Sweden.

3.2.2. The Distribution of Heat Availability within the Range of Fraxinus Excelsior in Scandinavia

The only native ash species in the northern part of Europe is European ash (F. excelsior) [26]. Heat availability is below $700^{\circ} \mathrm{AGDD}_{10}$ in the most part of Norway, Sweden, and Finland (Figure 7). There is a hope that these regions could potentially become the refuges for F. excelsior, where ash trees could escape from A. planipennis. In Denmark, Estonia, southern regions of Sweden and regions along the southern coasts of Norway and Finland, $\mathrm{AGDD}_{10}$ is from 700 to $800{ }^{\circ} \mathrm{C}$, i.e., about the minimum recorded in the territories occupied by A. planipennis. 
3.2.3. The Distribution of Heat Availability within the Range of Fraxinus Excelsior in British Isles

Fraxinus excelsior is common over the whole British Isles [26]. Our calculations have shown that $\mathrm{AGDD}_{10}$ in Ireland, Scotland, Northern Ireland, the most part of Wales and the northern half of England is less than $700^{\circ}$ (Figure 8).

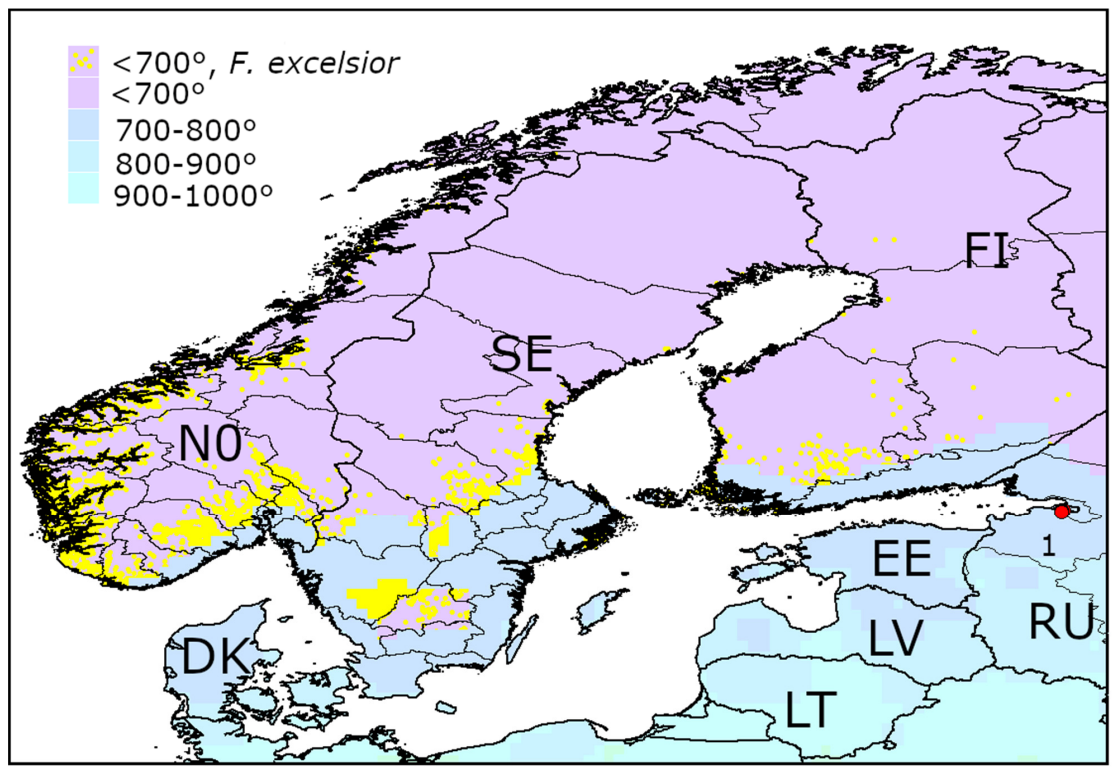

Figure 7. Occurrences of Fraxinus excelsior in the territories with $\mathrm{AGDD}_{10}$ below $700^{\circ}$ in Northern Europe. Mean AGDD 10 per year in 2003-2020 is indicated with colours (see the legend). DKDenmark, EE-Estonia, FI-Finland, LT—Lithuania, LV—Latvia, NO_Norway, RU—Russia, SESweden. 1-occurrences of Agrilus planipennis in Saint Petersburg. The information about the occurrences of F. excelsior was obtained from Global Biodiversity Information Facility [30-32].

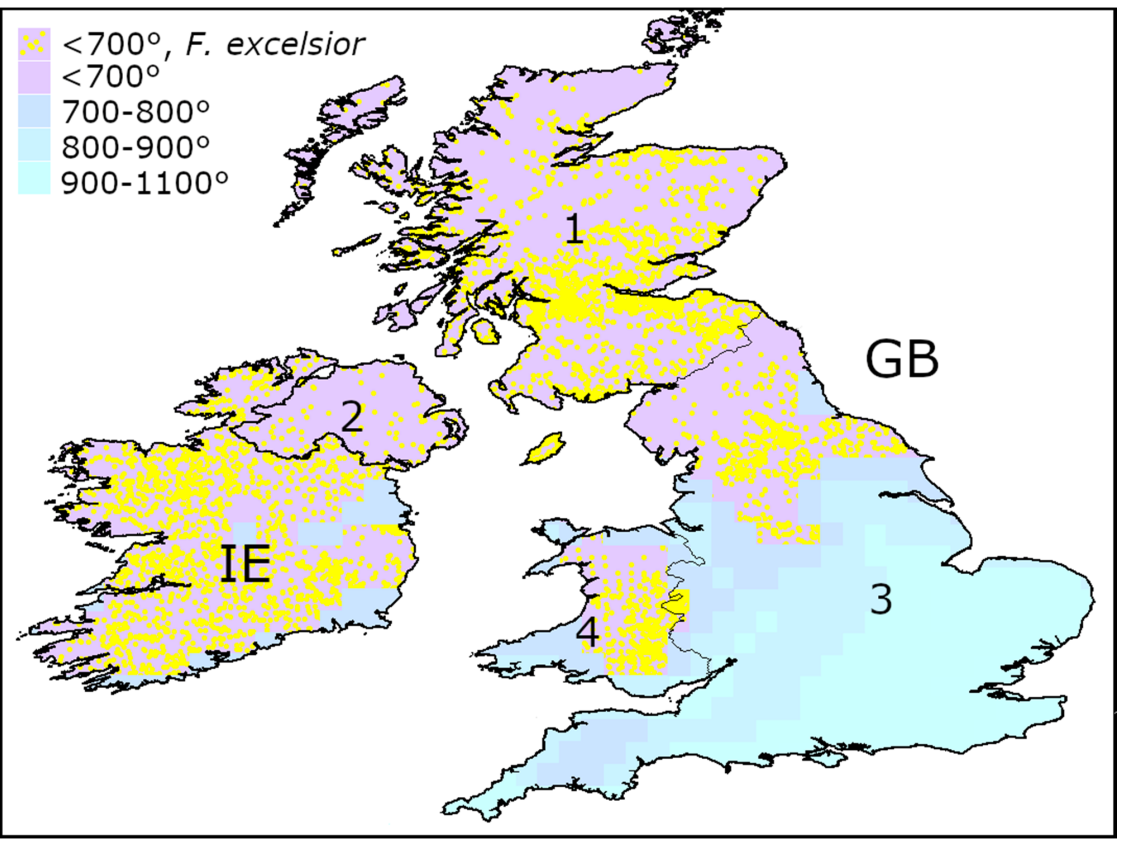

Figure 8. Occurrences of Fraxinus excelsior in the territories with $\mathrm{AGDD}_{10}$ below $700^{\circ}$ in British Isles. GB-Great Britain, IE-Ireland. 1-Scotland, 2-Northern Ireland, 3-England, 4-Wales. Mean $\mathrm{AGDD}_{10}$ per year in 2003-2020 is indicated with colours (see the legend). The information about the occurrences of F. excelsior was obtained from Global Biodiversity Information Facility [33-36]. 


\section{Discussion}

\subsection{Heat Availability as a Limiting Factor of A. planipennis Range}

Our data indicate that low heat availability could potentially limit the future spread of A. planipennis in Northern Europe. This conclusion is in accordance the conclusion by Webb et al. for the British Isles [19]. These authors calculated that northern half of the British Isles is unlikely to provide a suitable environment for $A$. planipennis to establish, because the $\mathrm{GDD}_{10}$ threshold of the start of the emergence of adults $\left(230^{\circ} \mathrm{GDD}_{10}\right.$ accumulated from 1 January) and the threshold of the peak of adult emergence $\left(500^{\circ} \mathrm{GDD}_{10}\right)$ are not met within a calendar year or are met in autumn [19].

It seems that the potential distribution of $A$. planipennis in Europe is similar to the current distribution of the two-spotted oak buprestid Agrilus biguttatus Fabricus. Agrilus biguttatus is widespread throughout Europe but reaches its northern-most limit in southern Sweden and in the northern half of the UK [16]. The host plants of A. biguttatus (Quercus spp.) are usual over the whole British Isles and in Scandinavia. However, the distribution of $A$. biguttatus is thermally limited with heat availability likely to be restrictive, rather than lethal summer or winter temperatures [16].

Prognoses that predict environmental suitability based on current location of cases for a pest that is still expanding into new regions may underestimate the area over which successful establishment is possible. However, our prognosis is based not only on the occurrences in invasive ranges in America and Europe, which are still expanding, but also on the occurrences in the native range in Asia, which is not expanding. The minimum $\mathrm{AGDD}_{10}$ in all three continents is almost the same (about $700^{\circ}$ ). Therefore, it seems that this figure is close to the minimum heat availability necessary for A. planipennis establishment. It is known that adult female A. planipennis body size (length and mass) depends on heat availability. The colder is the region, the smaller are adult females [37]. This phenotypic plasticity allows $A$. planipennis to survive in the colder regions. However, smaller A. planipennis females produce fewer eggs [37]. Obviously, the limit of this phenotypic plasticity exists: if the heat availability is too low, females are not able to survive or produce enough eggs for the establishment of the population

4.2. Comparison of Low Heat Availability and Minimum Winter Temperature as Limiting Factors of A. planipennis Potential Distribution

It is interesting that low winter temperature and low heat availability pose different limitations to the potential range of A. planipennis in Europe (Figure 9).

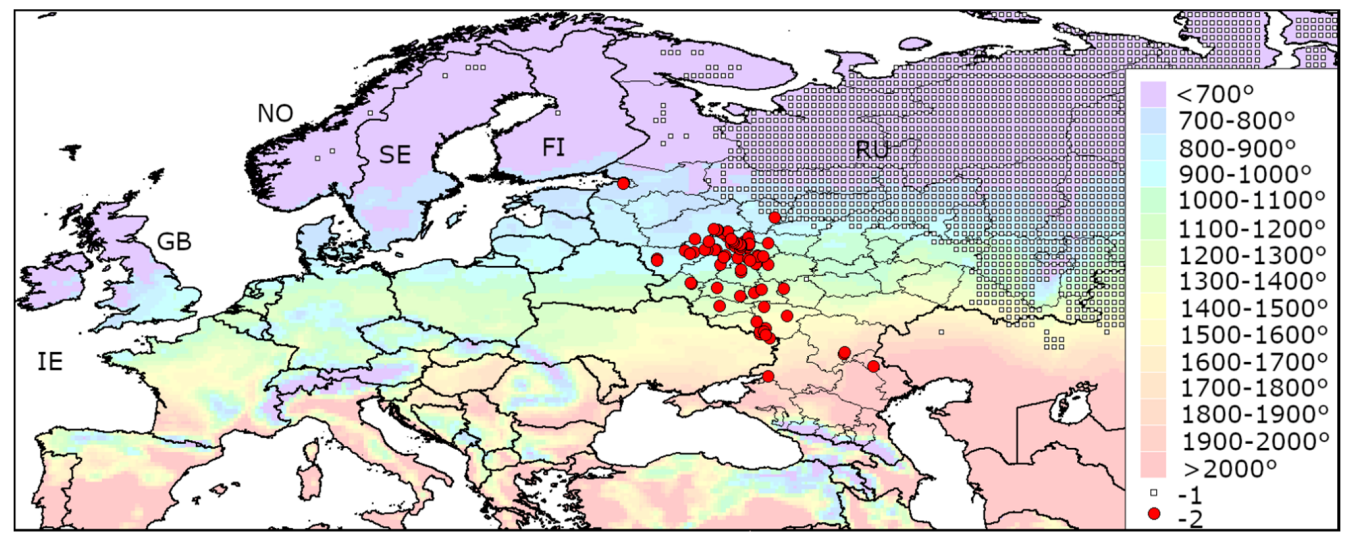

Figure 9. Distribution minimum winter temperature and heat availability in Europe. Mean $\mathrm{AGDD}_{10}$ per year in 2003-2020 is indicated with colours (see the legend). 1-territories, which are not suitable for Agrilus planipennis establishment because of the extreme winter cold [15], 2-localities of A. planipennis. FI-Finland, GB-Great Britain, IE-Ireland, NO-Norway, RU-Russia, SE-Sweden.

Our previous calculations have shown A. planipennis populations survive in the territories where the minimum daily temperature is above $34^{\circ} \mathrm{C}$, but do not survive in the 
territories where the daily temperature is below $34^{\circ} \mathrm{C}$ [15]. Temperature below $34^{\circ} \mathrm{C}$ is not rare in the east of European Russia but is extremely rare in Western Europe. Therefore, winter cold could limit of A. planipennis spread in the east of European Russia but could probably not limit its spread in Western Europe. Our current calculations have shown that fortunately the spread of the pest in the north of Europe could be potentially limited by low heat availability.

\subsection{Perspectives for Future Researches}

Variation in frequency and intensity of surveillance for A. planipennis between regions means that, for some areas, we can be less confident that a lack of report means that the pest is absent. The surveys of ash trees in the northern regions of European Russia and in the Far East are necessary for obtaining more detailed information about distribution of A. planipennis in the North.

$\mathrm{AGDD}_{10}$ in the high-altitude regions of the Alps, Pyrenees, Carpathians and Caucasus is less than $700^{\circ}$. The more detailed calculations of heat availability with higher resolution and the comparison with the high-resolution map of the distribution of ash trees (Fraxinus excelsior, F. ornus and F. angustifolia) are necessary to assess whether some highaltitude regions could become potential refuges of ash trees from $A$. planipennis.

Warmer temperatures appear to have contributed to recent northward range shifts of some native wood-boring forest pests in Europe, including jewel beetles (Coleoptera: Buprestidae): Coraebus florentinus Herbst and Agrilus sulcicollis Lacordaire [16]. Therefore, the future warming could potentially affect the spread of A. planipennis to the North. The analysis of the possible impact of the future climate change on the potential spread of A. planipennis is a perspective for future research.

It is known that the duration of the life cycle of $A$. planipennis depends on the temperature: in the warmer regions, the life cycle is usually 1 year, while in the colder regions it is 2 years [23]. It is important to reveal in what regions of Europe the potential development could be 1 year, because in such regions the spread of $A$. planipennis could be faster than in others. The estimation of the potential duration of the life cycle in different parts of Europe is also a perspective for future research.

\section{Conclusions}

1. Minimum $\mathrm{AGDD}_{10}$ recorded in the localities of $A$. planipennis in the three continents are almost the same: $714^{\circ}$ in Asia, $705^{\circ}$ in North America, and in $711^{\circ}$ Europe. Agrilus plenipennis has been never recorded in the regions with $\mathrm{AGDD}_{10}$ below $700^{\circ}$.

2. In the majority of Europe, $\mathrm{AGDD}_{10}$ is more than $700^{\circ}$. Therefore, low heat availability would probably not limit the spread of $A$. planipennis in most of European countries.

3. Heat availability in most regions of Norway, Sweden, Finland, and Ireland and in the northern half of Great Britain is less than $700^{\circ}$. If the phenotypic plasticity would not allow the pest to overcome this threshold, $A$. planipennis would potentially not establish in these regions. Therefore, Fraxinus excelsior could potentially escape from A. planipennis in these regions.

Supplementary Materials: The following are available online at https:/ / www.mdpi.com/article/10 .3390/insects13010052/s1, Table S1: Localities, where A. planipennis has been recorded in Asia, North America and Europe; File S1: Detailed description of the calculations of the mean AGDD 10 . Table S2: Results of calculations: the mean AGDD $_{10}$ per year in 2003-2020 in each grid square.

Author Contributions: Conceptualization, M.J.O.-B.; validation, A.O.B.; investigation, M.J.O.-B.; resources, A.O.B.; writing-Original draft preparation, M.J.O.-B.; writing-Review and editing, A.O.B.; visualization, M.J.O.-B.; funding acquisition, A.O.B. All authors have read and agreed to the published version of the manuscript.

Funding: This research was funded by RUSSIAN SCIENCE FOUNDATION, grant number 22-24-00166.

Institutional Review Board Statement: Not applicable. 
Data Availability Statement: All data generated during this study are in the electronic supplements (Supplementary Materials).

Acknowledgments: We are grateful to our son A.A. Bieńkowski (The faculty of Computational Mathematics and Cybernetics of Lomonosov Moscow State University, Russia) for help with the mathematical treatment.

Conflicts of Interest: The authors declare no conflict of interest. The funders had no role in the design of the study; in the collection, analyses, or interpretation of data; in the writing of the manuscript, or in the decision to publish the results.

\section{References}

1. Emerald Ash Borer Informative Network. Available online: http://www.emeraldashborer.info/ (accessed on 6 October 2021).

2. Volkovitsh, M.G.; Bieńkowski, A.O.; Orlova-Bienkowskaja, M.J. Emerald Ash Borer Approaches the Borders of the European Union and Kazakhstan and Is Confirmed to Infest European Ash. Forests 2021, 12, 691. [CrossRef]

3. Orlova-Bienkowskaja, M.J.; Volkovitsh, M.G. Are native ranges of the most destructive invasive pests well known? A case study of the native range of the emerald ash borer, Agrilus planipennis (Coleoptera: Buprestidae). Biol. Invasions 2018, 20, 1275-1286. [CrossRef]

4. Haack, R.A.; Jendek, E.; Liu, H.; Marchant, K.R.; Petrice, T.R.; Poland, T.M.; Ye, H. The Emerald Ash Borer: A new exotic pest in North America. Newsl. Mich. Entomol. Soc. 2002, 47, 1-5.

5. Izhevskii, S.S. Threatening Findings of the Emerald ash Borer Agrilus planipennis in the Moscow Region. Available online: http:/ / www.zin.ru/Animalia/Coleoptera/rus/agrplaiz.htm (accessed on 23 October 2021).

6. Commission Delegated Regulation (EU) 2019/1702 of 1 August 2019 Supplementing Regulation (EU) 2016/2031 of the European Parliament and of the Council by Establishing the List of Priority Pests. OJ L 260:8-10. Available online: http:/ / data.europa.eu/ eli/reg_del/2019/1702/oj (accessed on 23 October 2021).

7. Schans, J.; Schrader, G.; Delbianco, A.; Graziosi, I.; Vos, S. Pest survey card on Agrilus planipennis. EFSA Support. Publ. 2020, 17, 1945E. [CrossRef]

8. Orlova-Bienkowskaja, M.J.; Bieńkowski, A.O. Modeling long-distance dispersal of emerald ash borer in European Russia and prognosis of spread of this pest to neighboring countries within next 5 years. Ecol. Evol. 2018, 8, 9295-9304. [CrossRef] [PubMed]

9. Musolin, D.L.; Selikhovkin, A.V.; Peregudova, E.Y.; Popovichev, B.G.; Mandelshtam, M.Y.; Baranchikov, Y.N.; Vasaitis, R. NorthWestward expansion of the invasive range of emerald ash borer, Agrilus planipennis Fairmaire (Coleoptera: Buprestidae) towards the EU: From Moscow to Saint Petersburg. Forests 2021, 12, 502. [CrossRef]

10. Majorov, S.R.; Bochkin, V.D.; Nasimovich, Y.A.; Shcherbakov, A.V. Alien Flora of Moscow and Moscow Region; KMK Publishing House: Moscow, Russia, 2012.

11. Baranchikov, Y.N.; Seraya, L.G.; Grinash, M.N. All European ash Species are Susceptible to Emerald ash Borer Agrilus planipennis Fairmaire (Coleoptera: Buprestidae)-A Far Eastern Invader. Sib. J. For. Sci. 2014, 6, 80-85. Available online: https://xn--8 0abmehbaibgnewcmzjeef0c.xn--p1ai/upload/iblock/4be/4becfc1c0c3b3e232f28bd64691d9fac.pdf (accessed on 23 October 2021). (In Russian).

12. Dang, Y.Q.; Zhang, Y.L.; Wang, X.Y.; Xin, B.; Quinn, N.F.; Duan, J.J. Retrospective analysis of factors affecting the distribution of an invasive wood-boring insect using native range data: The importance of host plants. J. Pest Sci. 2021, 94, 981-990. [CrossRef]

13. Valenta, V.; Moser, D.; Kuttner, M.; Peterseil, J.; Essl, F. A high-resolution map of emerald ash borer invasion risk for southern central Europe. Forests 2015, 6, 3075-3086. [CrossRef]

14. Flø, D.; Krokene, P.; Økland, B. Invasion potential of Agrilus planipennis and other Agrilus beetles in Europe: Import pathways of deciduous wood chips and MaxEnt analyses of potential distribution areas. EPPO Bull. 2015, 45, 259-268. [CrossRef]

15. Orlova-Bienkowskaja, M.J.; Bieńkowski, A.O. Minimum winter temperature as a limiting factor of the potential spread of Agrilus planipennis, an alien pest of ash trees, in Europe. Insects 2020, 11, 258. [CrossRef] [PubMed]

16. Bale, J.S. Insects and low temperatures: From molecular biology to distributions and abundance. Philos. Trans. R. Soc. Lond. B Biol. Sci. 2002, 357, 849-862. [CrossRef] [PubMed]

17. Reed, K.; Denman, S.; Leather, S.R.; Forster, J.; Inward, D.J. The lifecycle of Agrilus biguttatus: The role of temperature in its development and distribution, and implications for Acute Oak Decline. Agric. For. Entomol. 2018, 20, 334-346. [CrossRef]

18. Afonin, A.N.; Musolin, D.L.; Egorov, A.A.; Selikhovkin, A.V. Possibilities of further range expansion of the emerald ash borer Agrilus planipennis (Coleoptera: Buprestidae) in the North-West of European Russia: What factors will limit the invasive range? In Proceedings of the Arctic Congress, Saint Petersburg, Russia, 12-16 September 2016; Abstract Book. Moilanen, O., Ed.; University of the Arctic/University of Oulu: Oulu, Finland, 2016; p. 100.

19. Webb, C.R.; Mona, T.; Gilligan, C.A. Predicting the potential for spread of emerald ash borer (Agrilus planipennis) in Great Britain: What can we learn from other affected areas? Plants People Planet 2021, 3, 402-413. [CrossRef]

20. Orlova-Bienkowskaja, M.J.; Drogvalenko, A.N.; Zabaluev, I.A.; Sazhnev, A.S.; Peregudova, E.Y.; Mazurov, S.G.; Komarov, E.V.; Struchaev, V.V.; Martynov, V.V.; Nikulina, T.V. Current range of Agrilus planipennis Fairmaire, an alien pest of ash trees, in European Russia and Ukraine. Ann. For. Sci. 2020, 77, 29. [CrossRef] 
21. GBIF.org GBIF Occurrence Download: Agrilus planipennis, Canada and the USA. 23 October 2021. Available online: https: / / doi.org/10.15468/dl.8ab2yd (accessed on 23 October 2021).

22. Copernicus Climate Change Service (C3S): C3S ERA5-Land Reanalysis. Copernicus Climate Change Service. Available online: https:/ / cds.climate.copernicus.eu/cdsapp\#!/home (accessed on 23 October 2021).

23. Orlova-Bienkowskaja, M.J.; Bieńkowski, A.O. The life cycle of the emerald ash borer Agrilus planipennis in European Russia and comparisons with its life cycles in Asia and North America. Agric. For. Entomol. 2016, 18, 182-188. [CrossRef]

24. Brown-Rytlewski, D.; Wilson, M.A. Tracking the emergence of emerald ash borer adults. In Emerald ash Borer Research and Technology Development Meeting; Mastro, V., Reardon, R., Eds.; 2004 USDA Forest Service Publication FHTET-2004-15; USDA Forest Service: Washington, DC, USA, 2004; pp. 13-14.

25. Hijmans, R.J.; Guarino, L.; Cruz, M.; Rojas, E. Computer tools for spatial analysis of plant genetic resources data: 1. DIVA-GIS. Plant. Gen. Res. Newsl. 2001, 127, 15-19.

26. Caudullo, G.; Welk, E.; San-Miguel-Ayanz, J. Chorological maps for the main European woody species. Data Br. 2017, 12, 662-666. [CrossRef] [PubMed]

27. DIVA GIS Free Spatial Data. Available online: https:/ / www.diva-gis.org/Data (accessed on 6 October 2021).

28. Yurchenko, G.I.; Turova, G.I.; Kuzmin, E.A. To distribution and ecology of emerald ash borer (Agrilus planipennis Fairmaire) in the Russian Far East. AI Kurentsov's Ann. Meml. Meet. 2007, 18, 94-98. (In Russian)

29. GBIF.org (17 October 2021) GBIF Occurrence Download: Fraxinus mandshurica. Available online: https://doi.org/10.15468/dl. fcx7xc (accessed on 23 October 2021).

30. GBIF.org (12 October 2021) GBIF Occurrence Download: Fraxinus excelsior, Norway. Available online: https://doi.org/10.15468 /dl.y2yent (accessed on 23 October 2021).

31. GBIF.org (12 October 2021) GBIF Occurrence Download: Fraxinus excelsior, Sweden. Available online: https://doi.org/10.15468 / dl.wvqynz (accessed on 23 October 2021).

32. GBIF.org (12 October 2021) GBIF Occurrence Download: Fraxinus excelsior, Finland. Available online: https://doi.org/10.15468 /d1.8vq3wa (accessed on 23 October 2021).

33. GBIF.org (13 October 2021) GBIF Occurrence Download Fraxinus excelsior, Ireland. Available online: https://doi.org/10.15468/dl. utx369 (accessed on 23 October 2021).

34. GBIF.org (13 October 2021) GBIF Occurrence Download Fraxinus excelsior, Great Britain 1. Available online: https://doi.org/10.1 $5468 /$ dl.9nzaj9 (accessed on 23 October 2021).

35. GBIF.org (13 October 2021) GBIF Occurrence Download Fraxinus excelsior, Great Britain 2. Available online: https://doi.org/10.1 $5468 /$ dl.gxqfja (accessed on 23 October 2021).

36. GBIF.org (13 October 2021) GBIF Occurrence Download Fraxinus excelsior, Great Britain 3. Available online: https:/ /doi.org/10.1 $5468 /$ dl.qfwr4b (accessed on 23 October 2021).

37. Marshall, J.M.; Miller, M.A.; Lelito, J.P.; Storer, A.J. Latitudinal variation in body size of Agrilus planipennis and relationship with fecundity. Agric. For. Entomol. 2013, 15, 294-300. [CrossRef] 